\title{
JIU VALLEY'S MINING ACTIVITY AS AN IDENTITY CONSTRUCTION
}

\author{
Mariana Eleonora ANGHEL \\ University of Petroșani, Romania \\ mary_anghel@yahoo.com
}

\begin{abstract}
This article focuses upon an approach that is specific to the identity construction of the mining activity in the Jiu Valley while considering demographic movements as a result of the process of making the mining units efficient. The contribution and social responsibility of the decisional factors with a view to outlining a model of social development and to providing a functional balance of the identity modelling of the area becomes a goal of tremendous importance in sociological analysis. Acknowledging the mutations having come out within the configuration of the area represents an important step towards the identification and drawing out of a series of solutions capable to contribute to the revitalization of the region and to determine added value at the level of the community through capitalizing all natural and human resources at a higher standard.
\end{abstract}

Keywords: profession, demographic movement, restructuring, social responsibility, change.

\section{Introduction}

Sociological analyses employed while approaching the identity construction of the social space start from identifying the circumstances and factors that influence and enable the economic and social development of the region. Meanwhile, both the economic and social context and the political context, which contributed to the expansion of mining activities, should be considered. As a consequence, we consider that the idea of identity belonging represents an important variable too, while approaching social participation modalities. The description of social reality through emphasizing the mutations having come out in the area as a result of the social and political changes determines, owing to its form, content and consciousness, an identity model specific for the area.

The answer to questions such as "Why Jiu Valley?" or "Which is the specific feature of this community?" and "What makes this area different from other regions?" is generally correlated directly with the process of industrial development or, more specifically, with the development of the mining industry.

The process of the growth of mining activity had a major contribution upon the complex development of the social space, also determining the growth of other connected activities.

\section{Mining, between a production activity and an institutional system}

The mining institution is one of the oldest organisational structures as a form of human activity. The mining industry had begun its development from ancient times paralleling the development of humankind, as it had to face the growing and diverse demands for raw materials. The industrial revolution determined the growth of mining extraction. The $20^{\text {th }}$ century led to a tremendous growing of mining 
exploitations owing to the favourable technical and economic characteristics of the time: complex mechanization, highly productive machines, and reduced costs. Under such circumstances, owing to the wide-spreading of mining, local communities displayed a spectacular institutional development. As far as this aspect is concerned, institutional development appeared to have determined medium term positive effects upon the communities; yet, the less favourable effects determined by the social and political changes or the long term effects upon the environment were not considered.

As far as the institutional aspect is concerned, the National Pit Coal Company in Petrosani was assimilated by Hunedoara Energy Group Company, both of them functioning as joint-stock companies having the Romanian State as a Sole ShareHolder. Beginning with 2015, the company operates as a functional institutional organism subordinated to the Ministry of Energy, Small Companies and Business Environment and dealing with the production, providing, and distribution of electric energy relying on pit coal as well as with carrying out research and maintenance activities [7].

When considering the complexity of the processes and phenomena, determined by the varied features and characteristics of a series of organizational mutations, the need for a more detailed knowledge of the resources involved and of the effects determined by the analysed activity comes out. Meanwhile, such an approach should also enable the objective choice of the most efficient manner of adapting to the new organizational structures. Accordingly, let's remember the numberless management and organizational restructuring processes at the level of the mining institution as well as the outsourcing of the various administrative activities (hostels, canteens, security services, and informatics services).

In accordance with a series of specialized studies, the means enabling public organizations to function more efficiently implies the taking over of the model of private management. Management represents a set of beliefs and practices developed within organizations as a strategy of improving their performance. In the opinion of Peter Drucker, managers and management turn institutions into performing structures and, in order not to enter a descendant path, innovation should be implemented, targeting groups, organizations or communities [4]. The characteristics of modern organizations are directly connected with the particular traits and features of the management of the public field, the understanding, analysis and description of this field being a must for the carrying out of a coherent process of administrative reform. The process of openness and boosting of public policy has determined the change of the attitude of pressure groups, which are an active part of the decisional process.

Public domain belongs to the people and is administered by the State (government), while the private domain is constituted within the general framework of the market, involving private ownership and profit making. In accordance, as far as social organizing is concerned, two large fields in society result: the public field and the private fields. As a consequence, the organizations existing within a society belong to three branches: public, private for profit, and private non-profit. Non-profit organizations are, in fact, constituted at the intersection between the public field and the private field owing to the fact that they are private as far as ownership and profit generation are concerned but they are public owing to their goals. The differentiation between organizations along this axis represents an important indicator enabling the grasping and illustration of a series of major changes having occurred within the organizational milieu during the last decades [3].

The tendency towards remodelling certain already existent organizational forms as well as the coming out of new types of 
organization may be explained through their representing a response to the change dynamics within the present-day society, or through their being an attempt at giving an answer to the most pronounced incertitude in the environment. The idea according to which the adopting of a series of specific organizational forms reflects the period during which they were created, meaning that, in any given period of time, the variation of organization forms is determined by the specific existing conditions during that given period [6].

\section{Professional and demographic prospect in the development of the Jiu Valley}

The ethno-demographic specificity of the area widened after the beginning of coal industrial exploitation. Coal exploitation represented the justification of the area's existence as an urban and industrial centre. The populating of the Jiu Valley occurred through two massive processes of colonization, besides natural growth. The first process of colonization occurred during the $16^{\text {th }}$ and $18^{\text {th }}$ centuries, while the second one began in the second half of the $19^{\text {th }}$ century. During the second period, the industrial exploitation of coal developed, which consisted in an important demographic growth. That demographic growth was determined by the natural growth of the population and by the second continual process of colonization, accompanied by the phenomenon of fluctuation, which turned the Jiu Valley into a geographic space where all the ethnic groups, religions, and individuals coming from Romania's counties, and even neighbouring peoples were represented, in different proportions. Another characteristic was population gathering within several centres that developed owing to industrial activity, a process that had as a result the building of colonies for workers, land planning and creation of an adequate superstructure [2].
Mining development has determined the inevitable coming out in the area of other activities directly or indirectly connected with it, determining the incoming of various social and professional groups belonging to the same areas or to different ones, besides miners and their families. Depending on the mining evolution data, the Jiu Valley basin developed as an integrated structure, displaying more or less positive consequences upon population: dynamics, structure, living standards.

The industrial revolution had a double impact over mining, owing to the fact that mining was both a field where scientific and technical discoveries could be implemented and a provider of raw materials required for the development of industrial branches and transportation, capable of strongly influencing the development of a series of geographical regions. Mining activity contributed to the building of an identity model and influenced the fields of the social, economic, political, and cultural milieus. Among the investments made at the time, we should also remember the urban and social-cultural preoccupations: the building of new homes for clerks, church schools, cultural and leisure spaces, which, besides the developments in the mining field, contributed to the creation, in the Jiu Valley, of an integrated industrial structure, displaying its own specialized labour, able to face the demands of complex activities. The 1989 events determined a vast process of social change, which included the social, economic, and political fields. The manner according to which, at the organizational level, the changes were planned, implemented, and coordinated within the social system had a powerful impact upon the Jiu Valley mining during all these years. Owing to the mono-industrial characteristics of the area, the employees of the mining exploitations, during the period 1990-1996, represented about 20\%; in the case the employees of auxiliary units is added to this percentage, then the share of 
those who were effectively employed in the mining system reached almost one third. After 1996, in only one year, a sudden decrease of the number of employees has occurred: a total of 16,477 disposed persons, only in the case of the mining exploitations, and 18,910 individuals restructured together with those belonging to the auxiliary units. Due to the importance of coal exploitation within the economy of the area, the Jiu Valley was (and it still is) assimilated with mining. Beginning with the 1997 disposing, the Jiu Valley came to be called by a series of analysts "the laboratory of Romanian economy" or "poverty bag", while journalists used to call it "the weeping Valley" [5].

With strong influences upon the economic and social life, mining industry underwent a series of powerful economic pressure from other branches of the economy; due to this fact, mining activity had to face significant quantity and quality changes that involved its institutional, management, technological, and life quality structures determining the demographic decline of the community.

\section{Methodological substantiation and the perception regarding the Jiu Valley's future of those who work in mining}

As far as methodology is concerned, the research represents the object of my doctoral thesis and focuses upon the analysis of the institutional dynamics of the social space and upon the effects of this dynamics upon the multiple restructurings having occurred in mining during the period 1990-2012, which represented the fundamentals of the sociological approach. The research included 273 subjects belonging to the operational field and 22 subjects belonging to the management field, representing $5 \%$ of the total population investigated in June 2013. The use of several methods was necessary, namely: sociological inquiry based on questionnaire, directed interview guide, documents analysis, and non-structured observation [1].

When starting from the institutional reforming of restructuring the mining activity that has been affecting the Jiu Valley during the last 20 years, we come across a series of challenges, which also represent the main preoccupation and focus of all the social actors in the analysed area and regard the economic re-launching of mining and region as well as the development of tourism as an alternative domain or of other fields of activity.

The research shows that most $(74 \%)$ of the subjects consider that, without mining, the Jiu Valley's future is questionable. The incertitude that dominates the collective mental is determined, to a large extent, by the fact that mining activity was in the Jiu Valley the main source of labour absorption during a very long period of time and other activities were developed in connection with this field. The attempt at motivating this incertitude that regards the future of the whole area of the Jiu Valley shows: lack of alternatives, of development strategies and investors, which determine social and economic issues, such as: unemployment increase, area's depopulation, demographic aging, and decrease of the living standards. The opinions of the subjects assert that mining was and still is the sole activity able to employ a large labour mass and that the termination of this field turns the Jiu Valley into a "dead area".

On the other hand, there is a very small part (10) who considers that the area of the Jiu Valley is not going to witness an uncertain future in the case mines are terminated. They see other opportunities, such as: the development of alternative activities, the growth of the business environment, and territory migration towards areas which are able to offer viable alternatives for professional achievement and labour reconversion. All these reasons mentioned previously are part of the expectations of the social actors in the analysed area. 
The analysis of the association of the variable dealing with the uncertain future of the Jiu Valley without mining with the variables with which it significantly correlates shows that, in general, those who support the termination of the mines and those who do not consider the continuation of the mining activities as a necessity suppose that the Jiu Valley might also have a future despite mining disappearance. At the opposite pole, there are those who consider that the Jiu Valley will have no future in the case mines are terminated; they also consider that mining conditions declined after restructuring began, supporting the need to continue mining activities.

As far as the employees of the mining units are concerned, an increased optimism may be perceived in connection with the future of the Jiu Valley without mining only in the case of EH Lonea; the situation may be explained owing to the fact that this mining unit has as employees a lot of individuals who own agriculture lands, pastures, and forests, a fact that makes them more confident; in accordance, these workers are sustainable even when they lack the incomes from the activity deployed at the mining units.

\section{Conclusions}

The following aspects come out of the previously displayed data: decisional factors should understand the need for change and innovation that can occur when there is a confluence between the values undergoing change and economic conditions, namely between the construction of an identity existential profile of the basic profession in the analysed area and the need for social innovation that takes into account this construction. It is then important to identify a series of medium and long term acting directions, with a view to creating real alternatives for labour absorption, for professional reconversion or for an adequate preservation of the value and attitude patterns built in time. Such an approach is motivated by the fact that the Jiu Valley developed owing to population gathering in a series of centres that grew in connection with industrial activity, a process which had as a result the building of dwelling houses, land planning and urbanization, the creation of an adequate superstructure or health and educational institutions.

\section{References}

[1] Anghel Mariana Eleonora, Natalitate și mortalitate instituţională în Valea Jiului - O perspectivă sociologică asupra mineritului din Valea Jiului, Timișoara, 2013.

[2] Baron Mircea, Cărbune şi societate în Valea Jiului (perioada interbelică)", Editura Universitas, Petroşani, 1998, pp. 32-44.

[3] Corici Miron, Aplicaţii ale sociologiei economice în managementul resurselor umane, Tipografia Universităţii de Vest, Timişoara, 2008, p. 99- 102.

[4] Drucker, Peter, The Esential Drucker - selecţie din lucrările de management ale lui Peter F. Drucker, Editura Meteor Press, Bucureşti, 2010, pp.14-20.

[5] Fulger Ioan Valentin, Valea Jiului după 1989, spaţiu generator de convulsii sociale, Editura Focus, Petroşani, 2007, pp.14-17.

[6] Vlăsceanu Mihaela, Organizaţii şi comportament organizaţional, Editura Polirom, Iaşi, 2003, pp. 89-93.

[7] http://www.cenhd.ro/index.php/act-constitutiv 